TORSTEN WILHOLT

\title{
LUDWIG BOLTZMANN'S MATHEMATICAL ARGUMENT FOR ATOMISM
}

[Manuscript version. The original publication appeared in History of Philosophy of Science - New Trends and Perspectives, ed. by Michael Heidelberger and Friedrich Stadler, Dordrecht etc.: Kluwer 2002 (=Vienna Circle Institute Yearbook 9/2001), 199-211.]

In recent years, the philosophy of Ludwig Boltzmann has become a point of interest within the field of History of Philosophy of Science. Attention has centred around Boltzmann's philosophical considerations connected to his defence of atomism in physics. In analysing these considerations, several scholars have attributed a pragmatist stance to Boltzmann. In this paper, I want to argue that, whatever pragmatist traits may be found in Boltzmann's diverse writings, his defence of atomism in physics can not be analysed this way. In other words, I wish to show that he did not defend atomism as "preferable for its practical virtues", as has been alleged. ${ }^{1}$ On the contrary, Boltzmann considered the atomist picture to be indispensable-more precisely, an indispensable prerequisite for making the application of continuous differential equations an understandable enterprise.

Boltzmann's ideas related to this line of reasoning are scattered across his writings. Thus, what I label his 'mathematical argument' for atomism is a rather loosely arranged set of views. Additionally to the aim formulated above, it is a second objective of this paper to bring together various historical details relating to the mathematical argument and find a reading that is coherent in itself and with Boltzmann's other philosophical opinions. A third aim is then (at the end of the paper) to sketch an important limitation of Boltzmann's thus reconstructed case for atomism.

\section{THE ViRTUE OF ATOMisM}

As a beginning, let me remind you of one of Boltzmann's better-known essays on this subject, his 'On the Indispensability of Atomism in Natural Science' (first published in 1897). My thesis that Boltzmann argued for the indispensability of atomism and not merely for its pragmatic superiority is on a very superficial level reinforced by the title of the essay. But on a deeper level, 
the argument in this central essay is not so unambiguous. Let me, without further quotations, sketch a very obvious way to read that argument.

The argument is mainly directed against the mathematical phenomenologists, who demand the abandonment of atomist principles and their replacement by the idea of a physical continuum. The continuum idea in question is the mathematical continuum concept as it is manifested in the application of real analysis in theoretical physics. However, Boltzmann claims, the phenomenologists thereby obscure the discontinuous foundations of the continuum concept underlying the differential calculus, which derives from the mathematical concept of limit. This concept, if applied to physical reality, must from Boltzmann's point of view be understood as follows: the limit of a function is established by increasing a certain number (of particles, of sections into which an interval is divided) until further increment of that number would not have any "noticeable" influence on the result any more. So, for Boltzmann, to forget about these foundations and take the differential equations themselves as the most straightforward representation of reality (as the mathematical phenomenologists do) means only to make an additional assumption: the assumption, that is, that however much our means of observation improves and however more subtle the differences "noticeable" for us become, we will never chance upon a difference between the measured facts and the magnitudes given by mathematical (infinitary) limits. For Boltzmann, atomism is the position which does not make that additional assumption, and since he holds the assumption to be totally unwarranted, the mathematical phenomenologists go further beyond the observable facts than the atomists do. Thus, atomism is the most natural stance for a scientist applying the differential calculus to nature.

So far, Boltzmann's reasoning provides an argument that atomism is preferable with respect to the background assumption that the scientific image should contain as few arbitrary elements as possible. This rhetoric is, of course, designed to defeat his scientific adversaries Mach, Ostwald et al. with their own weapons. However, I must concede, it does not add up to an argument for the indispensability of atomism, because 'making fewer arbitrary assumptions' is a feature that may make a theoretical picture preferable, but not automatically indispensable.

\section{THE INDISPENSABILITY OF ATOMISM}

Fortunately, Boltzmann's argument contains a further, though less obvious and less clear element. The essay discussed so far also contains claims to the effect that the idea of a continuum in nature would be incomprehensible without an atomistic foundation: 
Atomism seems inseparable from the concept of the continuum. The reason why Laplace, Poisson, Cauchy and others started from atomistic considerations is evidently that in those days scientists were as yet more clearly conscious that differential equations are merely symbols for atomistic conceptions so that they felt a stronger need to make the latter simple. ${ }^{2}$

Here it is no longer 'atomism vs. the continuum' but 'no continuum without atomism'. Contrary to the aforementioned line of reasoning, where the continuum picture was just like the atomist picture but with one more arbitrary and unnecessary assumption, it is now claimed to be in need of an atomistic interpretation.

Boltzmann returned to this leitmotif many times. The continuum itself is thereby taken to represent the idea of actually infinite divisibility. But in physics, infinity can only be viewed as a "Grenzübergang," a limit-transition. ${ }^{3}$ This is how he represented this core idea in his 1904 address to the Scientific Congress in St. Louis:

[W]e cannot define infinity in any other way than as the limit of ever growing finite magnitudes, at least nobody so far has been able to establish an intelligible concept of infinity in any other way. ${ }^{4}$

For Boltzmann, this implied that it is indispensable to understand not only the infinite in terms of the finite, but also the continuum in terms of the discrete. Let's turn again to the 'Indispensability' essay of 1897, where he states the following:

Do not imagine that by means of the word continuum or the writing down of a differential equation, you have acquired a clear concept of the continuum. On closer scrutiny the differential equation is merely the expression for the fact that one must first imagine a finite number; this is the first prerequisite, only then is the number to grow until its further growth has no further influence. ${ }^{5}$

Obviously, this view requires clarifications. Analysis as applied in physics evidently presupposes the actual continuum of real numbers. It is essential that for any monotone and bounded sequence, the set of real numbers contains the actual limit towards which the sequence converges, and not just enormously many elements of the sequence until further growth is not "noticeable" anymore. (Otherwise, real analysis wouldn't be Cauchy complete.) It is therefore even characteristic for real analysis that it can not be reduced to the finite in the way Boltzmann envisages.

Is he thus suggesting that the mathematical continuum is somehow an unjustified concept and that science should distance itself from real analysis? Fortunately not. Nowhere does he make this suggestion, and he goes on to apply real analysis like any other physicist. How then are we to understand his 
assertion that in physics, we have to conceive of the continuous differential equations as "symbols for atomistic conceptions"?

To get further elucidation on this, one has to turn to the lecture course on Natural Philosophy that Boltzmann gave in the winter term of 1903/04. ${ }^{6}$ There, a difference between Boltzmann's philosophy of pure and applied mathematics becomes apparent. He naturally introduces infinitary concepts of pure mathematics and even calls it a "legitimate claim" that mathematics be in principle in a position to grasp the infinite and the "actually continuous". ${ }^{7}$ But when he turns to a closer inspection of infinitary mathematics as explicated by Cantor's set theory, he makes it clear that this amounts to no more than a "game with concepts". ${ }^{8}$ As I will lay out in a little more detail in section 4, Boltzmann thought that such merely conceptual constructions, not directly modelled on experience, were inadvertently fallible and ambiguous if applied to reality. Thus, to preserve certitude of scientific inference, applied analysis has to be given a finite, discontinuous interpretation. (As Boltzmann wrote in 1897, the "practical utility" of infinitary methods are not to be called into question, but they are "epistemologically inferior to atomistic conceptions". ${ }^{9}$ )

While a more extensive treatment of Boltzmann's reasons for this claim will have to wait for a moment, we may for now retain the following moral as a tentative interpretation of the claim that "differential equations are merely symbols for atomistic conceptions": there is nothing wrong with the actual mathematical continuum as such, it is only in its application to natural phenomena that it has to be accompanied by an atomistic conception of the underlying reality (in order to prevent ambiguity). Such an atomistically understood reality can of course not be accurately reflected by continuous differential equations. But descriptions in terms of differential equations can be seen as symbols for atomistic conceptions in so far as they can serve to give us good approximations to the truths of an indefinitely (but not infinitely) finegrained discontinuous reality. In fact, Boltzmann suggested just this picture when he spoke of a possible discontinuity of time during his exposition of the general laws of motion in his lectures on mechanics:

Perhaps our formulae are only very closely approximate expressions for average values that can be constructed from much finer elements and are not strictly speaking differentiable. As to that, however, there are so far no indications from experience. ${ }^{10}$

This leads us to another point of clarification. The atomism at stake in the debate around the turn of the century was, of course, an atomism of matter. Yet Boltzmann's argument is directed against continuous concepts as such and thus promotes a more thoroughgoing atomism, including discontinuous time. Boltzmann mostly buries this aspect in the footnotes. In an extensive footnote to 
the 'Indispensability' essay, he imagines a world of enormously many packed spheres that evolve through discontinuous time. He concludes:

If it were possible to find such a picture that showed more comprehensive agreement than ordinary atomism, the picture would thereby be justified. Thus the view of atoms as material points and of forces as functions of their distance is no doubt provisional but must at present be retained failing a better one. ${ }^{11}$

In short: even atomistic physics as practised by Boltzmann is not only approximative (because it still applies continuous equations to a discontinuous reality) but also provisional (because it falls short of a thoroughly atomistic conception and remains restricted to an atomism of matter).

Let me summarise the picture that emerges from the interpretation I have sketched in this section: without an atomistic conception of the underlying reality, continuous differential equations are rooted in mere games with concepts and remain fallible and ambiguous. Therefore, atomism is indispensable for physical science if it is to be saved from ambiguity. There still remains a lot to say about why Boltzmann held these convictions. Before I turn to that question, I wish to respond to a possible objection.

\section{ATOMISM: PREFERABLE OR INDISPENSABLE?}

My claim that Boltzmann really wanted to argue for the indispensability of atomism depreciates the other argument that can be inferred from the 1897 essay, i.e. that atomism is preferable, on the ground of its making fewer arbitrary assumptions, as explained in section 1, to a mere rhetorical device. An obvious objection to my analysis arises: Why should one accept the suggestion that it's the argument for preferability which has only rhetorical character, while the indispensability of atomism for unambiguous reasoning about the physical continuum constitutes a genuine and fundamental argument of Boltzmann's? Could it not equally well be just the other way round, so that Boltzmann's indispensability considerations turn out to be a rhetorical over-intensification of his plea for preferability?

This objection would in fact fit in well with a very common account of Boltzmann's philosophical activity in the 1890's. This account stresses the fact that during that time, Boltzmann was facing an increasing influence of antimetaphysical opposition to the (trans-conscious) reality of atoms, brought up by Mach, Ostwald and others. This threatened the core of his physical work and thinking: kinetic theory and physical discontinuity. Therefore, it is often said, he adopted a series of diverse and sometimes incompatible philosophical positions, with the one and only aim of being in the strongest possible position 
to defend the core of his scientific work: atomism. ${ }^{12}$ This account is sometimes applied to his picture theory of scientific representation and to his philosophy of language sounding proposals to cleanse science of 'meaningless' metaphysical questions. Extending this to his indispensability idea seems to add up to a nice objection to my reading: the talk of the indispensability of atomism for our understanding of the physical continuum would then merely be the strongest possible rhetorical device, which Boltzmann pragmatically adopted for the purpose of defending his research programme.

My belief that this is not the case and that there is more to his indispensability considerations is based on my account of how Boltzmann came to think about the indispensability of atomism in the first place. The idea that in physics, infinity can only be viewed as a limit-transition, presented itself to Boltzmann at least 20 years before the 'Indispensability' essay was published. As I will now explain, I believe that it emerged directly from the concrete conceptual problems of his own research in theoretical physics.

Whereas usually Boltzmann is said to have ignored philosophy before the mid-1880's, the indispensability idea surfaces as early as 1877, in his famous paper on the relation between the second theorem of thermodynamics and the theory of probability. It contains a proof of the theorem which we today call Boltzmann's relation, $S=k \log W$. This important result relates the concept of entropy $(S)$ of a gas in a certain macrostate to the probability $(W)$ of that macrostate. This probability is in turn defined via the relative number of equiprobable microstates corresponding to each respective macrostate. The microstates in question are energy distributions among the molecules of the gas. However, since the kinetic energy that each molecule can assume is a continuous quantity, there are of course infinitely many possible energy distributions corresponding to each macrostate. Therefore, the rough and slightly incorrect characterisation of the concepts involved which I have just given, though it captures the intuitive idea behind the relation between thermodynamics and probability, strictly speaking involves an impossible operation: the quantitative comparison between infinite numbers.

This is how Boltzmann actually proceeded in order to circumvent this difficulty: he first assumed that there is only a finite set of discrete energy values that each molecule can adopt, and only afterwards calculated the mathematical limits which result from infinitely increasing the number and "concentration" of discrete energy values. While this may be quite an ordinary mathematical procedure, it is important to see how Boltzmann himself commented on it in the paper:

Even if this way of dealing with the problem seems to be very abstract at first sight, with most suchlike problems it leads the quickest way to the goal, and if one considers that all infinite in 
nature never means anything other than a limit-transition, then one cannot at all conceive of the infinite variety of velocities that each molecule is capable of adopting in any other way, unless as the limiting case which occurs when each molecule can adopt more and more velocities. ${ }^{13}$

As already mentioned above, the italicised expression is a phrase that he keeps on using into his late writings, where it is his slogan for the view that continuous equations presuppose atomistic conceptions which can then be conceived as indefinitely, but not infinitely fine-grained. For two reasons, I take the 1877 paper to confirm my reading that Boltzmann entertained the thought that atomism is indispensable to our understanding of the continuum as a serious element of his physical Weltbild, and not only as a rhetorical device. Firstly, it is obvious that the core of the idea, viz. that "all infinite in nature never means anything other than a limit-transition" is directly related to indispensable problem-solving techniques in his own concrete work as a theoretical physicist. Secondly, and more importantly, he had explicitly stated it long before he first engaged in philosophical and rhetorical battles with energeticists, mathematical phenomenologists and other anti-metaphysical opponents. ${ }^{14}$

\section{Why Does the Physical ContinuUm PResuppose A DiscontinuOUS CONCEPTION?}

I shall therefore now turn to a major problem within Boltzmann's indispensability considerations. As we have seen, he bases them on his conviction that continuous equations presuppose finite and discrete interpretations; in his words: that all infinite in nature can only be understood as a limit-transition. But this principle is itself not explicitly justified in the 1877 paper, nor in most of the other places where it is invoked. Boltzmann almost seems to have thought it self-evident. Nevertheless, important motivating ideas for the principle can be found in Boltzmann's philosophy, even if only in his later philosophical prose. In my opinion, two different lines of thought capable of serving as explanations for the aforementioned principle can be extracted from Boltzmann's writing. For both these lines, the only place where they are elaborated is the above-mentioned course on Natural Philosophy.

The first of the two lines of reasoning starts in the fourth lecture with the following remark:

It is self-evident that we cannot define the simplest concept, the concept of number, because we cannot resolve it into simpler concepts. ${ }^{15}$ 
As Boltzmann goes on to explain, the concept in question is, more precisely, that of the positive whole numbers. He sees it as basic and grounded in the practice of counting. How much of it is inherited, and how much learned, he finds hard to tell. In any case, we have acquired familiarity with the operations on positive whole numbers. It is only by our deliberate intent to extend the scope of these operations that we construct the other kinds of numbers: fractions as well as negative, irrational and imaginary numbers. ${ }^{16}$ Positive whole numbers, on the contrary, have through constant experience made their way into our "forms of thought", which Boltzmann characterises as follows:

... forms of thought, which have through outside influence developed in our brain, in our psyche, and these forms of thought have always led us to correct results; thereby they have become fixed forms of thought. ${ }^{17}$

From this psychologistic position, it is only a very small step to the conclusion that since the experience of counting which informs our laws of thought is always a finite experience, only finite concepts can be completely understood by our thus conditioned minds. Boltzmann nowhere makes this step explicit. He does however, with reference to Bolzano, contend that the infinite is a paradoxical notion. The paradox has, according to Boltzmann, not been solved by Cantor and the set theorists, who have only

... got used to it, they have only shown how the computational operations are to be arranged, so that one does not stumble over it, how one has to calculate in order to get around the paradoxes. ${ }^{18}$

I find it not too bold to round out this line of thought and give the following explanation: The concept of number, whether finite or infinite, is ultimately grounded in experience and in our laws of thought. And since our laws of thought have, through evolutionary aeons and throughout our individual experience, been informed by exclusively finite experiences, we can only understand the infinite in nature as a limit of increasing finite magnitudes. To our minds, the infinite as such remains an unfathomable paradox.

The second line of reasoning in question is highly original. It is based on an old problem in theoretical mechanics. Boltzmann does not refer to any specific texts in connection with this problem, but only mentions the name of the Slovenian mathematician Georg von Vega. But it can be shown that the problem goes back at least to Leonard Euler's Mechanica of $1736 .{ }^{19}$ It arises with a very simple mechanical setting: A point mass $A$ is, out of relative rest, attracted to a centre of force $S$. But Euler calculated the path of $A$ as a limiting case of the general form of motion governed by a single centre of force, elliptical motion. The small axis of the ellipse in Euler's calculation becomes infinitely small, and the ellipse infinitely eccentric; therefore, one apsis of the ellipse 
moves infinitely close to the focus at $S$. In the limiting case, $A^{\prime}$ 's starting point and $S$ form the end-points of a straight line. The result is that $A$ will move toward $S$ in a straight line, but upon arrival will be instantaneously reflected and move backwards toward the starting point. Euler accepted the result despite its counter-intuitive character.

Just as an aside, note that also Euler himself saw the reason for the conflict between common sense and his calculation in our limited understanding of infinitary reasoning. Yet, in contrast to Boltzmann, he trusted in mathematics to compensate for a lack of intuitive understanding:

Whatever may be, here one must trust in the calculation rather than in our judgement and declare that we do not deeply comprehend a leap if it occurs from the infinite to the finite. ${ }^{20}$

(He mentions a leap from the infinite to the finite because, according to his calculation, $A$ would momentarily acquire an infinite velocity at $S$.)

Georg von Vega was not content with Euler's result. His treatment of the case can be found in the third volume of his Lectures on Mathematics, first published in $1788 .{ }^{21} \mathrm{He}$ rejects Euler's calculation and simply calculates the motion of $A$ on a straight line right through $S$ by means of integration, starting from the inverse square force law. Vega himself is not really bothered that this law implies division by zero for the case when $A$ passes $S$, but Boltzmann tacitly corrects Vega's alternative treatment and introduces a tiny sphere around $S$ where the force is suspended.

Boltzmann describes this as a dilemma: If, in Euler's calculation, the small axis becomes infinitely small, and, in Vega's calculation, the sphere around $S$ becomes infinitely small, then they are both treatments of the same setting, but with directly opposite results, and it becomes impossible to decide which is the correct one. For Boltzmann, the dilemma is due to the infinitary reasoning involved. By restricting oneself to finitary reasoning, one can resolve the dilemma into a matter of differing cases: If we assume the small axis to be extremely, but not infinitely small, then $A$ will reverse its direction near $S$, describing an extremely eccentric elliptical motion around $S$. And if we assume a motion on a straight line and a very, but not infinitely small sphere around $S$ where the force is suspended, then $A$ will traverse $S$ and move on in the same direction.

In fact, if we never adopt anything infinite, if we only calculate with finite magnitudes that can be arbitrarily large, we never get to a contradiction. [...] But if $A$ coincides with $S$ and if Newton's law is valid till coincidence, [...] then I enter into set theory, into the really infinite, into the ultimate number $\omega$, and I encounter contradictions. ${ }^{22}$ 
This whole argument is concerned with such a specialised mechanical puzzle that one naturally doubts whether it can be intended as a serious general argument against infinitary reasoning about nature. But in Boltzmann's own fragmentary notes for the lecture, he suggests just this:

Vega. Collision [/thrust]: That is my proof that nature must be constructed atomistically. Not that nature must, but that we must think it thus, if we do not want to apply such absurd concepts as the ones from set theory, which lead to ambiguities. ${ }^{23}$

Thus, for Boltzmann, as I understand him, the Euler Vega dilemma shows nothing but the following: Our ability to reach secure and unambiguous conclusions is limited to reasoning about finite magnitudes. But this is at the same time a limitation of our understanding, because

... the purpose of thinking is to be able to unambiguously draw conclusions everywhere; therefore, we must seek to form our signs of speaking, writing and thinking in such a way, that we express ourselves unambiguously and understand ourselves unambiguously. ${ }^{24}$

So, since we cannot unambiguously draw conclusions about the infinite as such, we cannot understand it. Therefore, we can not understand the infinite in nature, unless we conceive of it as a limit-transition.

Is there a common idea behind the two lines of reasoning I have just been describing? I think so. Let me try to give an interpretation of how the diverse ideas of Boltzmann that I have presented so far belong together:

While, for Boltzmann, the Euler Vega dilemma seems to constitute exemplary evidence that we cannot unambiguously apply infinitary reasoning to nature, his psychologistic considerations about numbers may provide an explanation why this is the case. Numbers, being indefinable and basic forms of thought, have their justification in our and our ancestors' regular experience with physical objects. This is why we can securely apply finitary mathematics to nature. Infinitary mathematics, on the contrary, is the extension of the laws of thought to a realm far beyond the experience that first established them. And while this may be tolerable as a mere game with concepts, by reapplying this extended mathematics to nature, our judgement becomes ambiguous and fallible. To apply a phrase which Boltzmann often used: The laws of thought overshoot the mark. And since our ability to unambiguously draw conclusions is a prerequisite for understanding, we cannot truly understand the concept of an infinitely divisible continuum. Thus, an atomist interpretation of the continuum becomes indispensable to our understanding.

This is, of course, just an interpretation, though I have tried to stick as closely as possible to Boltzmann's own statements. Boltzmann himself often only hints at the connections between his diverse ideas. Furthermore, some 
central parts of these ideas, like e.g. the border between finitary and infinitary reasoning, are far from clear.

But these uncertainties notwithstanding, one thing should have become obvious: for Boltzmann, whether or not to adopt an atomistic understanding of nature is not a matter of free choice, to be decided by criteria of usefulness. There are serious constraints to our choice. Against the Kantian spirit prevailing among his contemporaries, Boltzmann conceives of these constraints as grounded in naturalistically understood laws of thought.

\section{CONCLUSION: LIMITS OF PSYCHOLOGISM}

The reader may have already stumbled over a caveat in one of the citations given above: Boltzmann claims to demonstrate not that nature must be constituted atomistically, but "that we must think it thus". This, I think, reflects Boltzmann's acknowledgement (at least in 1903), that his mathematical argument falls short of a case for realism about atoms.

As I have reconstructed the argument, the fact that our capacity to unambiguously draw conclusions is limited to the finite is rooted in our laws of thought. But laws of thought, even if conceived as conditioned by our evolutionary history, need not reflect the true constitution of nature. Thus the claim that an atomistic conception of nature is an indispensable precondition for an unambiguously founded science does not imply that nature must be discontinuous.

Boltzmann was well aware that the laws of thought he imagined need not be perfectly adapted to promoting our cognition of the truths of nature. He thought of them as a kind of naturalist version of the a priori, but without the necessity, as the following remark indicates:

One can call these laws of thought a priori because through many thousands of years of our species' experience they have become innate to the individual, but it seems to be no more than a logical howler of Kant's to infer their infallibility in all cases. ${ }^{25}$

On the contrary, Boltzmann suspected that evolution often favours features that are useful in some cases and then become so deeply entrenched in the organism's biological constitution that they cannot be given up if they turn out not to be appropriate in all circumstances.

This happens especially often with mental habits and becomes a source of apparent contradictions between the laws of thought and the world, and between those laws themselves. ${ }^{26}$ 
This shows that according to Boltzmann's own conception of laws of thought, they cannot be seen as reliably mirroring the nature that selected them; and the mathematical argument for atomism, in so far as it rests on the requirements posed by our laws of thought, cannot establish that this nature must really be constituted atomistically.

To be sure, the mathematical argument was not Boltzmann's only strategy for defending atomism. The main alternative is, of course, to present independent predictive and explanatory successes of the atomistic hypothesis. Today, this is often seen as the most promising argumentative strategy for scientific realism, ${ }^{27}$ and there are places where Boltzmann rests his case solely on this line of reasoning. ${ }^{28}$ However, in his later writings, he seems to have given preference to the mathematical argument. In the St. Louis address, he does indeed specify some explanatory successes of atomism, but then goes on to claim:

However, it is not all these facts and the consequences drawn from them that I wish to put forward here, for they cannot resolve the question as to the limited or infinite divisibility of matter. [...] Rather, we will [...] examine the formation of concepts itself in as unprejudiced a way as possible $[\ldots] \cdot .^{29}$

The statement is then followed by a short version of the mathematical argument. The citation shows that, though Boltzmann did realise that the mathematical argument was not the only possible case for atomism in physics, he considered it the strongest one, at least in his later years. And to the extent that the mathematical argument was Boltzmann's strategy for propagating atomism, his campaign cannot have been one for the reality of atoms. The argument as I have reconstructed it suggests that he was concerned with the secure and unambiguous foundations of physics rather than with scientific realism.

As a conclusion, I would like to stress once more that the textual evidence shows perspicuously that for Boltzmann, the constraints of our laws of thought were serious and inevitable. Therefore, the limitations of his naturalistic (or more precisely, psychologistic) reasoning as presented in this section must not be confused with an alleged problem-shift from "Do atoms exist?" to "Is atomism as a mental picture fruitful as the hard core of a scientific research programme?" as diagnosed by Yehuda Elkana. ${ }^{30}$ On the contrary, the atomistic conception is presented as indispensable (albeit in a psychological way) and not a question of pragmatic choice. Though naturalism and pragmatism have sometimes gone hand in hand in the history of philosophy, they did not do so in the philosophy of Ludwig Boltzmann - at least not in his defence of atomism, as I have intended to show in this paper. 


\section{NOTES}

${ }^{1}$ See, e.g., Henk de Regt, from whom the quotation is taken. 'Ludwig Boltzmann's Bildtheorie and Scientific Understanding', in: John Blackmore (Ed.), Ludwig Boltzmann: Troubled Genius as Philosopher. Dordrecht: Kluwer 1999 (= Synthese 119 (1-2)), pp. 113-134, p. 128. Cf. also Yehuda Elkana as cited below in note 30.

2 'Über die Unentbehrlichkeit der Atomistik in der Naturwissenschaft' (1897), quoted from the translation in Brian McGuinness (Ed.), Ludwig Boltzmann, Theoretical Physics and Philosophical Problems: Selected Writings. Dordrecht: Reidel 1974, p. 44.

${ }^{3}$ This is a formulation he chose in his lecture course on Natural Philosophy in 1903. Ilse M. Fasol-Boltzmann (Ed.), Ludwig Boltzmann, Principien der Naturfilosofi. Lectures on Natural Philosophy 1903-1906. Berlin etc.: Springer 1990, p. 189.

4 'Über statistische Mechanik' (1904), quoted from the translation in McGuinness (Ed.), op. cit., p. 169. He had already used a very similar formulation in his Lectures on Gas Theory in 1896, see Roman U. Sexl (Ed.), Ludwig Boltzmann Gesamtausgabe, Vol. 1: Vorlesungen über Gastheorie. Graz: Akademische Druck- u. Verlagsanstalt \& Braunschweig: Vieweg 1981, p. 5.

5 'Über die Unentbehrlichkeit der Atomistik in der Naturwissenschaft', loc. cit., p. 43.

${ }^{6}$ There is a transcript of Boltzmann's own fragmentary and for the most part hardly intelligible notes for this lecture course in existence, as well as an unknown student's detailed elaboration of it (both of which were published only fairly recently). In the following, I will mostly refer to the student's elaboration. Cf. Fasol-Boltzmann (Ed.), op. cit.

7 Ibid., p. 189.

8 Ibid., p. 194.

9 'Nochmals über die Atomistik' (1897), quoted from the translation in McGuinness (Ed.), op. cit., p. 54.

10 Vorlesungen über die Prinzipe der Mechanik, Teil I, quoted from the partial translation in McGuinness (Ed.), op. cit., p. 245 f.

11 'Über die Unentbehrlichkeit der Atomistik in der Naturwissenschaft', loc. cit., footnote 4, p. 52.

${ }^{12}$ For such an account of Boltzmann's philosophical activity, see e.g. John Blackmore: ‘Boltzmann and Epistemology', in: Blackmore (Ed.), op. cit., pp. 157-189.

13 "Wenn auch diese Behandlungsweise des Problems auf den ersten Anblick sehr abstrakt zu sein scheint, so führt sie doch bei derartigen Problemen meistens am raschesten zum Ziele, und wenn man bedenkt, daß alles Unendliche in der Natur niemals etwas anderes als einen Grenzübergang bedeutet, so kann man die unendliche Mannigfaltigkeit von Geschwindigkeiten, welche jedes Molekül anzunehmen imstande ist, gar nicht anders auffassen, es sei denn als den Grenzfall, welcher eintritt, wenn jedes Molekül immer mehr und mehr Geschwindigkeiten annehmen kann." “Über die Beziehung zwischen dem zweiten Hauptsatze der mechanischen Wärmetheorie und der Wahrscheinlichkeitsrechnung resp. den Sätzen über das Wärmegleichgewicht', in: Fritz Hasenöhrl (Ed.), Wissenschaftliche Abhandlungen von Ludwig Boltzmann, Vol. 2. Leipzig: Barth 1909, pp. 167 f., my translation, my italics. 
14 Apparently, some of Boltzmann's contemporaries did think that his argument suddenly appeared only in the 1890's. Thus in 1898, Georg Helm calls it "Boltzmann's new defence of atomism ..." (my italics, "Boltzmann's neue Verteidigung des Atomismus durch den Differentialbegriff"). Georg Helm, Die Energetik nach ihrer geschichtlichen Entwickelung. Leipzig: Veit 1898, p. 362.

15 "Es versteht sich von selbst, daß wir den einfachsten Begriff, den der Zahl nicht definieren können, denn wir können ihn nicht in einfachere Begriffe zerlegen." Fasol-Boltzmann (Ed.), op. cit., p. 163, my translation.

${ }^{16}$ Cf. ibid., $174 \mathrm{f}$.

17 "[...] Denkformen, welche sich durch die äußeren Einflüsse in unserem Gehirne, in unserer Psyche herausentwickelt haben, und diese Denkformen haben uns immer zu richtigen Resultaten geführt; dadurch sind sie zu feststehenden Denkformen geworden." Ibid., p. 168, my translation.

18 " [...] sie haben sich nur daran gewöhnt, sie haben nur gezeigt, wie die Rechnungsoperationen einzurichten sind, daß man nicht darüber stolpert, wie man zu rechnen hat, um über die Paradoxien herumzukommen." Ibid., pp. 189 f, my translation.

19 See Propositio 80, especially $\S$ 655, and confer also Propositio 32. Paul Stäckel (Ed.), Leonardi Euleri Opera Omnia, Ser. 2, Vol. 1: Mechanica sive motus scientia analytice exposita. Leipzig \& Berlin: Teubner 1912.

20 "Quicquid autem sit, hic calculo potius quam nostro iudicio est fidendum atque statuendum, nos saltum, si fit ex infinito in finitum, penitus non comprehendere." Stäckel (Ed.), op. cit., § 272, p. 88, my translation. This remark is contained in Euler's discussion of a different setting (assuming a $1 / r$ force law), but immediately followed by a reference to the case I am dealing with here, by which, as Euler claims, the quoted remark gets even more confirmed.

${ }^{21}$ See the Anmerk for $\S 230$, pp. 505 ff. in Georg von Vega, Vorlesungen über die Mathematik. Dritter Band, welcher die Mechanik der festen Körper enthält. 4th edition, Vienna: Tendler 1818.

22 "Faktisch kommen wir, wenn wir nie etwas Unendliches aufnehmen, wenn wir nur mit endlichen Größen rechnen, welche beliebig groß sein können, nie zu einem Widerspruch [...] Wenn aber A mit $\mathrm{S}$ zusammen fällt und bis zum Zusammenfallen das Newton'sche Gesetz gilt [...] komme ich in die Mengenlehre hinein, in das wirklich Unendliche, in die letzte Zahl $w$ [sic], und ich komme auf Widersprüche." Fasol-Boltzmann (Ed.), op. cit., p. 200, my translation.

23 “Vega. Stoß: Das ist mein Beweis, daß die Natur atomistisch konstruiert sein muß. Nicht, daß Natur muß, daß wir sie so denken müssen, wenn wir nicht so absurde Begriffe, wie die der Mengenlehre anwenden wollen, die zu Mehrdeutigkeiten führen." Ibid., p. 92, my translation.

24 "[...] der Zweck des Denkens ist ja, überall eindeutig schließen zu können; daher müssen wir unsere Sprach- Schrift- und Denkzeichen so zu bilden suchen, daß wir uns selbst eindeutig ausdrücken und uns selbst eindeutig verstehen." Ibid., p. 200, my translation.

25 'Über eine These Schopenhauers' (1905), quoted from the translation in McGuinness (Ed.), op. cit., p. 195.

26 'Über statistische Mechanik', loc. cit., p. 166. 
${ }^{27}$ Especially since Richard Boyd's 'On the Current Status of Scientific Realism', in: Erkenntnis 19 (1983), pp. 45-90.

${ }^{28}$ See, for a very nice example, his 'Über die Entwicklung der Methoden der theoretischen Physik in neuerer Zeit' (1899), translated in McGuinness (Ed.), op. cit., esp. pp. 98 f.

29 ‘Über statistische Mechanik', loc. cit., p. 169.

30 'Boltzmann's Scientific Research Program and its Alternatives', in: Yehuda Elkana (Ed.), The Interaction Between Science and Philosophy, Atlantic Highlands, N.J.: Humanities Press 1974, pp. 243-279, esp. p. 268. 